\title{
Serum lipids and coronary heart disease in British elderly
}

\author{
D.M. Mangion and S.S. Roy
}

Department of Medicine for the Elderly, Barnsley District General Hospital, Gawber Road, Barnsley S75 $2 E P, U K$

Summary: To assess the relationship between serum lipids and coronary heart disease (CHD) in an elderly population (mean age $=77.4 ;$ SEM \pm 0.4 ; range 70-92 years), serum total cholesterol (TC), high density lipoprotein cholesterol (HDL-C) and low density lipoprotein cholesterol (LDL-C) were measured in 84 (males = 52) subjects with evidence of definite myocardial infarction and 125 (males $=77$ ) age- and sex-matched controls free of CHD on Rose questionnaire and resting electrocardiogram.

On multivariate logistic regression analysis, CHD showed inverse association with HDL-C (odds ratio for decrease by 1 s.d. $=1.6, P=0.02$ ) in males and positive association with TC (odds ratio for increase by 1 s.d. $=1.8, P=0.03$ ) and LDL-C (odds ratio for increase by 1 s.d. $=1.8, P=0.04$ ) in females. Of the other variables only diabetes in males (odds ratio $2.4, P=0.05$ ) and left ventricular hypertrophy in females (odds ratio 8.8, $P=0.03$ ) were associated with $\mathrm{CHD}$.

The results suggest that further prospective studies to further evaluate the relation of serum lipids with CHD in this age group are indicated.

\section{Introduction}

Coronary heart disease (CHD) is the main cause of death in adults 65 years and older in the UK. ${ }^{1}$ In middle aged and younger populations, serum total cholesterol $^{2-6}$ and low density lipoprotein cholesterol $^{7,8}$ are well-recognized risk factors for CHD while high density lipoprotein cholesterol has a protective effect. ${ }^{9-12}$ The association of serum lipids with CHD in the elderly is less well defined. In this age group, total serum cholesterol was a risk factor for CHD in some $e^{13-17}$ but not all studies. ${ }^{18-22}$ Most studies $^{13-15,17,18,20-22}$ relate to American populations, and data in British elderly is limited and conflicting. ${ }^{16,19}$ Moreover, while high density and low density lipoprotein cholesterol may be better predictors of CHD than total cholesterol in subjects 50 years and older, ${ }^{10,11}$ few data exist on their relationship with CHD in elderly subjects. ${ }^{23}$ The relation of lipoprotein cholesterol with CHD in British elderly has not been examined previously.

A rational approach to any preventative care requires data on the population at risk. This study examines the association of serum total cholesterol and serum lipoprotein cholesterol with CHD in an elderly ( 70 years and older) British population.

Correspondence: D. Mangion, M.R.C.P.(UK), Taranaki Base Hospital, New Plymouth, New Zealand.

Accepted: 8 March 1993

\section{Methods}

Subjects and age ( \pm 2 years) and sex-matched controls were consecutive attenders at a general medical outpatient clinic. Subjects were patients with a recorded history of the first-ever definite myocardial infarction on WHO criteria (sequential electrocardiographic pathological $\mathrm{Q} / \mathrm{QS}$ wave changes and/or typical chest pain with sequential rise in serum aspartate aminotransferase, creatine phosphokinase and lactate dehydrogenase) ${ }^{24}$ occurring at age 70 years or older. All controls were free of coronary heart disease by Rose questionnaire and resting electrocardiogram (ECG) (Minnesota code 1-1-1 and 1-3-6 and 4-1 to 5-4 inclusive). ${ }^{25}$ All subjects and controls consenting to the study had a full clinical history and examination, a standard 12 lead electrocardiogram, chest $\mathrm{X}$-ray, haemoglobin estimation and biochemical estimation of renal and hepatic function.

Subjects and controls were excluded if: (a) they were on a low fat diet or lipid-lowering agent (subjects $=3$, controls $=1$ ); (b) were within 3 months of myocardial infarction or other acute illness or had known or suspected malignancy or chronic inflammatory condition or recent weight loss (subjects $=4$, controls $=13$ ); (c) had abnormal renal (serum creatinine $>120 \mathrm{mmol} / \mathrm{l}$ ) or liver function (serum bilirubin $>23 \mu \mathrm{mol} / 1$ and/or aspartate transferase $>45 \mathrm{IU} / \mathrm{l})$ or anaemia $(\leqslant 10 \mathrm{~g} / \mathrm{l})$ (subjects $=8$, controls $=14$ ); (d) were on medication possibly affecting glucose tolerance (sub- 
jects $=5$, controls $=9$ ); and (e) refused consent for the investigation (subjects $=3$, controls $=7$ ). In addition, controls were excluded if they were immobile unaided $(n=9)$.

A total of $84(78 \%)$ (males $=52,62 \%)$ subjects and 125 controls $(71 \%)$ (males $=77,62 \%$ ) were studied. All were white Caucasian. Mean age of subjects was 77.1 ( \pm 0.3 ) years (range 70-91 years) and of controls $77.7( \pm 0.4)$ years (range 70-92 years) $(P>0.05)$. In cases, mean time post myocardial infarction was $7.4( \pm 0.3)$ months.

Total and current cigarette smoking was expressed in cigarette pack years (one pack $=20$ cigarettes). Subjects were classified as current smokers if they had smoked within 5 years of myocardial infarction and controls within 5 years of the investigation; otherwise they were classified as past smokers. Sitting systolic and diastolic (Korotkoff phase 5) blood pressure (BP) was recorded in both arms, the mean of three readings in the arm with the higher reading being used for analysis. Hypertension was defined as a recorded systolic blood pressure $\geqslant 160 \mathrm{mmHg}$ and/or a diastolic blood pressure $\geqslant 95 \mathrm{mmHg}^{26}$ and/or a recorded history of anti-hypertensive treatment, criteria similar to those in the Framingham study. ${ }^{27}$ Body mass index (BMI) was expressed as weight (kilograms)/height (metres) ${ }^{2} .^{28}$ Waist circumference was measured at the level of the umbilicus and hip circumference at the level of the iliac crest. ${ }^{29}$ Left ventricular hypertrophy $(\mathrm{LVH})$ was assessed by ECG voltage criteria. ${ }^{25}$

Venous blood was taken for blood glucose, serum lipid and plasma fibrinogen estimation after a 16 hour overnight fast. In all subjects without a previous diagnosis of diabetes mellitus, venous blood was obtained at 1 and 2 hours following an oral $75 \mathrm{~g}$ glucose load (Fortical, Nutrica, Belgium). Diabetes mellitus and impaired glucose tolerance were diagnosed on WHO criteria. ${ }^{30}$

Venous blood glucose was estimated by the glucose oxidase method. Serum lipids were measured by automated enzymatic colorimetric methods using standard enzyme kits. High density lipoprotein cholesterol (HDL-C) was measured after precipitation of low density (LDL-C) and very low density lipoprotein cholesterol with phosphotungstic acid $/ \mathrm{MgCl}_{2}$ (Sigma Diagnostics, St Louis, USA). ${ }^{31}$ Cholesterol was measured by the cholesterol oxidase/peroxidase-aminoantipyrin method (Bio-Stat, USA) and triglycerides by the glycerol phosphate oxidase/peroxidase-aminoantipyrin method (Human mbH, Germany). Low density lipoprotein cholesterol was calculated by the Friedwald equation. ${ }^{32}$ Plasma fibrinogen was measured by a modification of the Claus method. ${ }^{33}$ The between batch coefficients of variation were: total cholesterol (TC) $2.0 \%$, HDL-C $3.7 \%$, triglycerides $1.1 \%(n=105)$ and fibrinogen $7.4 \%$ $(n=17)$.

Statistical analysis was by chi square, Student's $t \stackrel{\varrho}{\varrho}$ test, linear regression and multivariate logistical regression analyses ${ }^{34}$ using the SAS programme. ${ }^{35} \stackrel{\bar{Q}}{\varrho}$ Total cholesterol and LDL-C were analysed in $C$. separate models, since these were strongly cor- $\overrightarrow{\vec{F}}$ related $(r=0.81, P<0.0001)$. Separate models were also analysed for diabetes only and glucose intolerance (diabetes and impaired glucose tolerance together) and for current and total cigarette pack years as independent variables. Other independent variables common to all models were: age, sex, HDL-C, log triglycerides, systolic BP, hypertension, body mass index (BMI), waist/hip ratio, serum fibrinogen and LVH. Log triglycerides were used for analysis because serum triglycerides were non-normally distributed. Multivariate logistic regression was by a maximum likelihood backward elimination method. Age, TC and HDL-C and LDL-C were retained in all models and the least significant of the other variables was discarded in successive models. A $P$ value $\leqslant 0.05$ was taken as the criterion for retention in the model. The significance level was taken as $P \leqslant 0.05$ throughout. Odds ratios and $95 \%$ confidence limits were calculated from the beta coefficient and its standard error. ${ }^{34}$ Odds ratios for continuous variables were standardized for 1 standard devia tion change in the variable. Means are quoted os \pm SEM.

The study had ethical committee approval are all subjects gave informed consent.

\section{Results}

In both cases and controls, mean TC and log triglycerides were higher in females $(P<0.05)$ (Table I). Female cases had a higher LDL-C $(P<0.05)$ compared to males; levels in controls were similar $(P>0.05)$ (Table I). There was no sex difference $(P>0.05)$ of HDL-C in cases or controls (Table I). Age correlated inversely with TC and LDL-C both males (TC: $r=-0.053, P=0.02$; LDL-C: $r=-0.219, P=0.01$ ) and females (TC: $r=-0.094, P=0.001$; LDL-C: $r=-0.36, P=$ $0.0008)$. There was no association of age with HDL-C or log triglycerides in either sex $(P>0.05)$.

In males, HDL-C was lower and the prevalence of diabetes was higher in cases compared to $O$ controls $(P<0.05)$ (Table I). In females, LDL-C N was higher and HLD-C was lower in cases com- N pared to controls $(P<0.05)$ (Table I).

On multivariate analysis, CHD in males was related inversely to HDL-C and positively to $\frac{\odot}{\Phi}$ diabetes (Table II). In females, CHD was positively $\stackrel{?}{?}$ associated with TC, LDL-C and LVH (Table III). TO Standardized odds ratios and $95 \%$ confidence ${ }_{0}^{\circ}$ limits, adjusted for age, are presented in Table II 
Table I Distribution of variables in study population

\begin{tabular}{|c|c|c|c|c|}
\hline & \multicolumn{2}{|c|}{ Males } & \multicolumn{2}{|c|}{ Females } \\
\hline & Cases & Controls & Cases & Controls \\
\hline$n$ & 52 & 77 & 32 & 48 \\
\hline Age & $\begin{array}{r}76.8(0.7) \\
(70-88)\end{array}$ & $\begin{array}{c}77.2(0.6) \\
(70-89)\end{array}$ & $\begin{array}{r}77.6(1.0) \\
(70-91)\end{array}$ & $\begin{array}{c}78.4(0.7) \\
(70-92)\end{array}$ \\
\hline $\begin{array}{l}\text { SBP } \\
\text { (mmHg) }\end{array}$ & $\begin{array}{c}140.9(2.2) \\
(105-180)\end{array}$ & $\begin{array}{r}140.3(2.4) \\
(110-240)\end{array}$ & $\begin{array}{c}139.4(4.7) \\
(100-230)\end{array}$ & $\begin{array}{c}149.6(4.2) \\
(110-230)\end{array}$ \\
\hline $\begin{array}{l}\text { Hypertension } \\
(n(\%))\end{array}$ & $19(36)$ & $18(23)$ & $16(50)$ & $25(52)$ \\
\hline Diabetes $(n(\%))$ & $17(33)^{*}$ & $13(17)$ & $10(31)$ & $16(33)$ \\
\hline TPY & $\begin{array}{l}29.3(4.5) \\
\quad(0-155)\end{array}$ & $\begin{array}{r}35.1(3.5) \\
(0-180)\end{array}$ & $\begin{array}{r}16.5(5.4) \\
(0-150)\end{array}$ & $\begin{array}{c}14.8(3.6) \\
(0-94)\end{array}$ \\
\hline CPY & $\begin{array}{c}20.8(4.8) \\
\quad(0-155)\end{array}$ & $\begin{array}{r}18.7(3.4) \\
(0-180)\end{array}$ & $\begin{array}{c}10.3(3.3) \\
(0-57)\end{array}$ & $\begin{array}{c}9.5(2.8) \\
(0-69)\end{array}$ \\
\hline $\begin{array}{l}\text { TC } \\
(\mathrm{mmol} / \mathrm{l})\end{array}$ & $\begin{array}{l}5.8(0.2) \\
(3.1-11.8)\end{array}$ & $\begin{array}{r}5.6(0.1) \\
(2.8-8.4)\end{array}$ & $\begin{array}{c}6.8(0.2) \\
(4.2-10.3)\end{array}$ & $\begin{array}{r}6.4(0.3) \\
(3.5-9.8)\end{array}$ \\
\hline $\begin{array}{l}\text { HDL-C } \\
(\mathrm{mmol} / \mathrm{l})\end{array}$ & $\begin{array}{l}1.0(0.03)^{*} \\
(0.7-1.6)\end{array}$ & $\begin{array}{l}1.2(0.04) \\
(0.5-2.1)\end{array}$ & $\begin{array}{l}1.1(0.07) \dagger \\
(0.5-2.4)\end{array}$ & $\begin{array}{c}1.2(0.05) \\
(1.0-2.2)\end{array}$ \\
\hline $\begin{array}{l}\text { LDL-C } \\
\qquad(\mathrm{mmol} / \mathrm{l})\end{array}$ & $\begin{array}{l}4.0(0.2) \\
(1.4-9.5)\end{array}$ & $\begin{array}{r}3.7(0.1) \\
(1.5-6.4)\end{array}$ & $\begin{array}{l}4.7(0.3) \dagger \\
(1.1-7.9)\end{array}$ & $\begin{array}{r}4.1(0.2) \\
(1.5-7.1)\end{array}$ \\
\hline $\begin{array}{l}\text { Log triglycerides } \\
(\mathrm{mmol} / \mathrm{l})\end{array}$ & $\begin{array}{l}0.17(0.02) \\
(-0.2-0.5)\end{array}$ & $\begin{array}{r}0.15(0.02) \\
(-0.3-0.8)\end{array}$ & $\begin{array}{l}0.31(0.04) \\
(-0.1-1.0)\end{array}$ & $\begin{array}{r}0.27(0.03) \\
(-0.1-1.1)\end{array}$ \\
\hline $\begin{array}{l}\text { BMI } \\
\left(\mathrm{kg} / \mathrm{m}^{2}\right)\end{array}$ & $\begin{array}{l}25.0(0.5) \\
(14.9-36.7)\end{array}$ & $\begin{array}{c}24.3(0.5) \\
(14.4-33.8)\end{array}$ & $\begin{array}{l}25.9(0.9) \\
(15.7-35.4)\end{array}$ & $\begin{array}{c}26.7(0.7) \\
(28.2-26.7)\end{array}$ \\
\hline Waist/hip ratio & $\begin{array}{c}0.95(0.01) \\
(0.8-1.1)\end{array}$ & $\begin{array}{l}0.93(0.01) \\
(0.7-1.1)\end{array}$ & $\begin{array}{c}0.85(0.01) \\
(0.7-1.0)\end{array}$ & $\begin{array}{l}0.87(0.01) \\
(0.7-1.0)\end{array}$ \\
\hline $\begin{array}{l}\text { Fibrinogen } \\
(\mathrm{mmol} / \mathrm{l})\end{array}$ & $\begin{array}{r}338.5(11.7) \\
(190-580)\end{array}$ & $\begin{array}{c}347.9(11.5) \\
(165-720)\end{array}$ & $\begin{array}{r}342.6(14.1) \\
(210-570)\end{array}$ & $\begin{array}{c}368.9(16.5) \\
(180-720)\end{array}$ \\
\hline LVH $(n(\%))$ & $5(10)$ & $3(4)$ & $5(16)$ & $3(6)$ \\
\hline
\end{tabular}

Values in parenthesis are ranges. Values for continuous variables are means \pm SEM. ${ }^{*} P<0.05$ male cases compared to male controls; $\uparrow P<0.05$ female cases compared to female controls; $\mathrm{SBP}=$ systolic blood pressure; $\mathrm{TPY}=$ total cigarette pack years; $\mathrm{CPY}=$ current cigarette pack years; other abbreviations as in text.

for males and Table III for females.

Since the trends for the association of the different lipid fractions with CHD were similar in both sexes and the confidence limits for odds ratios overlap, analysis was repeated with both sexes pooled. On multivariate analysis adjusted for age and sex, CHD showed inverse relationship with HDL-C (beta $=-1.7898$, odds ratio for decrease by 1 s.d., $0.33 \mathrm{mmol} / 1=1.8,95 \%$ CL $1.3-2.6, P=$ 0.0005 ) and positive association with $\mathrm{TC}$ (beta $=$ 0.2226 , odds ratio for increase by 1 s.d., 1.42 $\mathrm{mmol} / \mathrm{l}=1.4,95 \% \mathrm{CL} 1.0-1.9, P=0.05), \mathrm{LDL}-\mathrm{C}$ (beta $=0.2786$, odds ratio for increase by 1 s.d., $1.27 \mathrm{mmol} / \mathrm{l}=1.3,95 \%$ CL $1.1-1.8, P=0.03$ ) and LVH (beta 1.4818, OR 4.4, 95\% CL 1.4-14.0, $P=0.01)$.

\section{Discussion}

In recent studies, total cholesterol measured in middle age was a risk factor for CHD in older age groups. ${ }^{13-17}$ Females were included in only two studies $^{13,14}$ and none-assessed lipoprotein cholesterol fractions. In the present study, on multivariate analysis CHD was associated inversely with HDL$\mathrm{C}$ in males and positively with TC and LDL-C in females. Diabetes in males and LVH in females were also associated with CHD.

This study is limited by its cross-sectional design and it may be argued that the associations demonstrated do not necessarily imply causation. However, the trends observed are consistent with those demonstrated in prospective studies. ${ }^{2-14}$ The definition of CHD in this study was restricted to definite myocardial infarction to allow for a more accurate diagnosis since the Rose questionnaire may be an unreliable indicator of CHD in this age group. ${ }^{36}$ Although this was a cross-sectional study, the age and sex distribution of serum lipids reflected those found in larger epidemiological studies. ${ }^{37,38} \mathrm{It}$ is recognized that alteration in serum lipids may occur as a result of illness, including myocardial infarction itself, or because of dietary or drug treatment to lower serum cholesterol. ${ }^{39}$ However, the exclusion criteria used in this study minimized this possibility. While subjects and controls were recruited from an outpatient popula- 
Table II Multivariate results in males

\begin{tabular}{lll}
\hline & Model 1 & Model 2 \\
\hline TC & & \\
Beta & 0.1977 & - \\
odds ratio & 1.3 & - \\
$95 \%$ CL & $0.8-1.8$ & - \\
$P$ & 0.19 & - \\
HDL-C & & \\
Beta & -1.6298 & -1.5027 \\
odds ratio & 1.6 & 1.6 \\
$95 \%$ CL & $1.1-2.4$ & $1.0-2.3$ \\
$P$ & 0.02 & 0.02 \\
LDL-C & & \\
Beta & - & 0.1991 \\
odds ratio & - & 1.3 \\
$95 \%$ CL & - & $0.9-1.9$ \\
$P$ & - & 0.2 \\
Diabetes & & \\
Beta & 0.8907 & 0.8782 \\
odds ratio & 2.4 & 2.4 \\
$95 \%$ CL & $1.0-5.9$ & $1.0-5.9$ \\
$P$ & 0.05 & 0.05 \\
\hline
\end{tabular}

Model 1 includes age, TC, HDL-C and diabetes; model $P=0.004$. Model 2 includes age, HDL-C, LDL-C and diabetes; model $P=\mathbf{0 . 0 0 3}$. Standardized odds ratio for continuous variables calculated for increase by 1 s.d. for TC (1.31 mmol/l) and LDL-C (1.19 mmol/l) and decrease by $1 \mathrm{~s} . \mathrm{d}$. for HDL-C $(0.32 \mathrm{mmol} / \mathrm{l})$.

Table III Multivariate results in females

\begin{tabular}{lll}
\hline & Model 1 & Model 2 \\
\hline TC & & \\
Beta & 0.4313 & - \\
odds ratio & 1.8 & - \\
$95 \%$ CL & $1.0-3.2$ & - \\
$P$ & 0.03 & - \\
HDL-C & & \\
Beta & -1.4274 & -1.3468 \\
odds ratio & 1.7 & 1.6 \\
$95 \%$ CL & $0.9-2.9$ & $0.9-2.9$ \\
$P$ & 0.07 & 0.1 \\
LDLC & & \\
Beta & - & 0.4398 \\
odds ratio & - & 1.8 \\
95\% CL & - & $1.0-3.2$ \\
$P$ & - & 0.04 \\
LVH & & \\
Beta & 2.1703 & 2.0131 \\
odds ratio & 8.8 & 7.5 \\
$95 \%$ CL & $1.3-60.8$ & $1.1-50.9$ \\
$P$ & 0.03 & 0.04 \\
\hline
\end{tabular}

Model 1 includes age, TC, HDL-C, LVH; model $P=0.01$. Model 2 includes age, HDL-C, LDL-C, LVH; model $P=0.01$. Standardized odds ratio calculated for increase by $1 \mathrm{s.d}$. for TC $(1.41 \mathrm{mmol} / \mathrm{l})$ and LDL-C $(1.35 \mathrm{mmol} / \mathrm{l})$ and decrease by $1 \mathrm{s.d}$. for HDL-C $(0.36 \mathrm{mmol} / \mathrm{l})$. tion rigorous screening excluded those with serious non-cardiovascular disease, particularly conditions likely to affect serum lipid levels. In cases, serum lipids were measured at least 3 months after myocardial infarction to avoid possible alteration of serum lipids as a result of the event ${ }^{39}$ None of the cases or controls studied was on dietary or drug treatment designed to alter serum cholesterol; the relatively few subjects excluded on these criteria possibly reflects current doubts on the validity of screening and treatment of elderly subjects for hyperlipidaemia. ${ }^{23}$

The sex-specific associations of TC, HDL-C and LDL-C with CHD demonstrated in the present study are consistent with recent reports suggesting that in the elderly $\mathrm{TC}^{14}$ and LDL-C ${ }^{40}$ are better predictors of CHD in females while low HDL-C is a better predictor in males. ${ }^{40}$ However, the trends were similar in both sexes, the confidence limits overlap and in sex-adjusted pooled analysis all lipid fractions showed relationship with CHD consistent with the sex specific analyses. Small numbers may partly account for failure to demonstrate statistical significance in sex-specific analysis. Also, the predictive power of TC declines with the age at which it is measured and improves with the duration of follow-up. ${ }^{16}$

In middle-aged British males TC was a better predictor of CHD than HDL-C when both were included in multivariate analysis, ${ }^{6}$ but mean $T E$ levels were higher than in the present study populis tion $(6.8 \mathrm{mmol} / 1$ in cases and $6.3 \mathrm{mmol} / \mathrm{l}$ in noncases). No similar data exist for British females. The independent inverse association of HDL-C with CHD has been demonstrated even at low levels of TC. ${ }^{11}$ The findings are consistent with those from prospective epidemiological studies demonstrating a better association of HDL-C with CHD than TC in males aged 50 years and older ${ }^{10,11}$ and demonstrate that the relationships persist in subjects aged 70 years and older. The standardized odds ratio for HDL-C in males in the present study is similar to that in younger males. ${ }^{6,7,10}$ High density lipoprotein cholesterol has been related to longevity and in subjects aged 85 years was a better predictor of mortality than TC over 5 year followup. ${ }^{41}$

Systolic blood pressure was related to CHD in some $^{14,15}$ but not all studies. ${ }^{13,21}$ The majority $(54 / 78,69 \%)$ of hypertensives in this study were on anti-hypertensive treatment and myocardial infarction may be accompanied by a fall in systolic blood pressure; ${ }^{42}$ these factors may account for the failure to find a relation between measured systolic blood prerssure and CHD in this study. Left ventricular mass, determined by echo cardiography, was an independent risk factor for development of CHD in elderly males and females, although systolic blood pressure was not. ${ }^{27}$ Left 
ventricular hypertrophy may more closely reflect long-term influences of hypertension and obesity than isolated measurements. ${ }^{27}$ In the present study the association of $\mathrm{LVH}$ with $\mathrm{CHD}$ was stronger in females.

While an increased risk of vascular disease in diabetics may partly be due to associated metabolic abnormalities, ${ }^{43}$ an independent association of diabetes with CHD was demonstrated in males in this study. Duration of diabetes was not assessed, since the prediagnosis duration is difficult to determine. Previous studies have shown a greater risk of CHD in females; ${ }^{14,44}$ the better association with males in this study may represent poorer survival in diabetic females. Diabetes has been inconsistently related to CHD in the elderly. ${ }^{13,14,19,21}$ However, these studies ${ }^{13,14,19,21}$ have not assessed glucose intolerance with glucose challenge, although the prevalence of glucose intolerance increases with age. ${ }^{45}$ Of diabetics in the present study, 13 males $(43 \%)$ and 11 females $(42 \%)$ were newly diagnosed.

Cigarette smoking was associated with CHD in the elderly in some $e^{14,15,19,21}$ but not all ${ }^{10,13,46}$ studies.
However, the relative risk of cigarette smoking declines with age perhaps reflecting earlier death in smokers and the stronger association of age itself with $\mathrm{CHD} .{ }^{46}$ Also, cigarette smoking may be more closely related to cardiac deaths than non-fatal events; ${ }^{47}$ cardiac death was not assessed in this study. Although previous studies ${ }^{48}$ have suggested that plasma fibrinogen is a cardiovascular risk factor in the older age groups, this has not been demonstrated in the present study. Waist hip ratio, a cardiovascular risk factor reflecting truncal obesity, ${ }^{29}$ has not previously been assessed in this age group. Recent analysis suggests that obesity is not an independent risk factor for atherosclerosis when other cardiovascular risk factors are included in analysis. ${ }^{49}$

This study demonstrates an association between serum lipids and CHD in British elderly and suggests that in this age group low HDL-C is a better predictor in males while TC and LDL-C are better predictors in females. Prospective studies to confirm these relationships in this age group are indicated.

\section{References}

1. Mortality Statistics. Cause. OPCS, DH2 no 15. HMSO, London, 1988.

2. Robertson, T.L., Kato, H., Gordon, T. et al. Epidemiologic studies of coronary heart disease and stroke in Japanese men living in Japan, Hawaii and California. Am J Cardiol 1977, 39: 244-249.

3. Stamler, J., Wentworth, D. \& Neaton, J.D. Is relationship between serum cholesterol and risk of premature death from coronary heart disease continuous and graded? Findings in 356222 primary screenees of the Multiple Risk Factor Intervention Trial. JAMA 1986, 256: 2823-2827.

4. Rose, G. \& Shipley, M. Plasma cholesterol concentration and death from coronary heart disease: 10 year results of the Whitehall study. $B r$ Med $J$ 1986, 293: 306-307.

5. Stokes, J., Kannal, W.B., Wolf, P.A., Cupples, L.A. \& D'Agostino, R.B. The relative importance of selected risk factors for various manifestations of cardiovascular disease among men and women from 35 to 64 years old: 30 years of follow up in the Framingham study. Circulation 1987, 75 (Suppl V): V-65-V-73

6. Pocock, S.J., Shaper, A.G. \& Phillips, A.N. Concentrations of high density lipoprotein cholesterol, triglycerides and total cholesterol in ischaemic heart disease. Br Med J 1989, 298: 998- 1002 .

7. Gordon, T., Kannel, W.B., Castelli, W.P. \& Dawber, T.R. Lipoproteins, cardiovascular disease and death - the Framingham Study. Arch Intern Med 1981, 141: 1128-1131.

8. Reed, D., Katsuhiko, Y. \& Kagan, A. Lipids and lipoproteins as predictors of coronary heart disease, stroke and cancer in the Honolulu Heart Program. Am J Med 1986, 80: 871-878.

9. Miller, N.E., Forde, O.H., Thelle, D.S. \& Mjos, O.D. The Tromso Heart Study - high density lipoprotein and coronary heart disease: a prospective case control study. Lancet 1977, i: 965-968.

10. Goldbourt, U. \& Medallie, J.H. High density lipoprotein cholesterol and incidence of coronary heart disease - the Israeli Ischaemic Heart Study. Am J Epidemiol 1979, 109: $296-308$
11. Castelli, W.P., Garrison, R.J., Wilson, P.W.F., Abbott, R.D., Kalousidaian, S. \& Kannel, W.B. Incidence of coronary heart disease and lipoprotein cholesterol levels - The Framingham Study. JAMA 1986, 256: 2835-2838.

12. Gordon, D.J., Probstfield, J.L., Garrison, R.J. et al. High density lipoprotein cholesterol and cardiovascular disease: four prospective American studies. Circulation 1989, 79: $8-15$.

13. Barrett-Connor, E., Suarez, L., Khaw, K.-T., Criqui, M.H. \& Wingard, D.L. Ischaemic heart disease risk factors after age 50. J Chronic Dis 1984, 37: 903-908.

14. Harris, T., Cook, E.F., Kannel, W.B. \& Goldman, L. Proportional hazard analysis of risk factors for coronary heart disease in individuals aged 65 or older. J Am Geriatr Soc 1988, 36: $1023-1028$

15. Benfante, R.\& Reed, D. Is elevated serum cholesterol a risk factor for coronary heart disease in the elderly? JAMA 1990, 263: 393-396.

16. Shipley, M.J., Pocock, S.J. \& Marmot, M.G. Does plasma cholesterol concentration predict mortality from coronary heart disease in elderly people? 18 years follow up in the Whitehall study. Br Med J 1991, 297: 89-92.

17. Rubin, S.M., Sidney, S. \& Black, D.M. High blood cholesterol in elderly men and the excess risk of coronary heart disease. Ann Intern Med 1990, 113: 916-920.

18. Chapman, J.M. \& Massey, F.J. The interrelationship of serum cholesterol, hypertension and body weight and risk of coronary disease. Results of the first ten years of the Los Angeles Heart study. J Chron Dis 1964, 17: 933-949.

19. Kennedy, R., Andrews, G. \& Caird, F. Ischaemic heart disease in the elderly. Br Heart $J$ 1977, 39: 1121-1127.

20. Welborn, T.A. \& Wearne, K. Coronary heart disease incidence and mortality in Bussleton with reference to glucose and insulin concentrations. Diabetic Care 1979, 2: 154-160.

21. Jajich, C.L., Ostfeld, A.M. \& Freeman, D.H. Smoking and coronary heart disease in the elderly. JAMA 1984, 252: $2831-2834$. 
22. Siegel, D., Kuller, L., Lazarus, N.B. et al. Predictors of cardiovascular events and mortality in the systolic hypertension in the elderly program pilot project. Am J Epidemiol 1987, 126: 385-399.

23. Beaglehole, R. Coronary heart disease and elderly people. $\mathrm{Br}$ Med J 1991, 303: 69-70.

24. World Health Organisation Regional Office for Europe. Public Health in Europe: 5. Myocardial infarction community register. WHO Annexe, Copenhagen, 1, 1976.

25. Rose, G.A. \& Blackburn, H. Cardiovascular Survey Methods. WHO monograph 56, 1968.

26. WHO. Arterial hypertension. Report of a WHO expert committee. WHO. Technical Report Series no. 628. WHO, Geneva, 1978.

27. Levy, D., Garrison, R.J., Savage, D.D., Kannel, W.B. \& Castelli, W.P. Left ventricular mass and incidence of coronary heart disease in an elderly cohort: the Framingham study. Ann Intern Med 1989, 110: 101-107.

28. Garrow, J.S. \& Webster, J. Quatlet's index as a measure of fatness. Int $J$ Obes 1985, 9: 147-153.

29. Larsson, B., Svardsudd, K., Welin, L., Wilhemsen, L., Bjorntorp, P. \& Tibblin, G. Abdominal adipose tissue distribution, obesity and risk of cardiovascular disease and death: 13 year follow up of participants in the study of men born in 1913. $\mathrm{Br}$ Med $J$ 1984, 288: 1401-1404.

30. World Health Organisation, Expert Committee on Diabetes. Technical Report Series no. 646. WHO, Geneva, 1978.

31. Marz, W. \& Gross, W. Analysis of plasma lipoproteins by ultracentrifugation in a new fixed angle rotor: evaluation of a phosphotungstic acid/ $\mathbf{M g C l}_{2}$ precipitation and quantitative lipoprotein electrophoresis assay. Clin Chim Acta 1986, 160: $1-18$.

32. Friedwald, W.T., Levy, R.I. \& Fredrickson, D.S. Estimation of the concentration of low density lipoprotein cholesterol in plasma without use of preparative ultracentrifuge. Clin Chem 1972, 18: 499-502.

33. Clauss, A. Rapid physiological coagulation method for the determination of fibrinogen. Acta Haem 1957, 17: 237-246.

34. Armitage, P. \& Berry, G. Statistical Methods in Medical Research, 2nd ed. Blackwell Scientific Publications, Oxford, 1987.

35. SAS Institute Inc. SAS User's guide: Basics version 5. SAS Institute Inc., Cary, NC, 1985.

36. Kitchen, A.H. \& Milne, J.S. Longitudinal survey of ischaemic heart disease in a randomly selected sample of older population. Br Heart $J$ 1977, 39: 889-893.
37. The Lipid Research Clinics Program Epidemiology Committee. Plasma lipid distributions in selected North American乞 populations: the Lipid Research Clinics Program Prevalence 3 Study. Circulation 1979, 60: 427-439.

38. Gordon, T. \& Shurtleff, D. The Framingham study, section 29. Means at each examination and interexamination varia-. tions of specified characteristics. DHEW Publication no. (NIH) 74-748. Washington, DC, 1974.

39. Ryder, R.E.J., Hayes, T.M., Mulligan, P., Kingswood, J.C.으 Williams, S. \& Owens, S.R. How soon after myocardiato infarction should serum lipids be assessed? Br Med J 1984, 289: $1651-1653$.

40. Zimetbaum, P., Frishman, W.H., Ooi, W.L. et al. Plasma@ lipids and lipoproteins and the incidence of cardiovascularn disease in the very elderly - the Bronx study. Arteriosclerosis Thrombosis 1992, 12: 416-423.

41. Nikkila, M. \& Heikkinen, J. Serum cholesterol, high densitylipoprotein cholesterol and five-year survival in elderly $\vec{\omega}$ people. Age Ageing 1990, 19: 403-408.

42. Kannel, W.B., Sorlie, P., Castelli, W.P. \& McGee, D. Blood pressure and survival after myocardial infarction: the Fram-3 ingham study. Am J Cardiol 1980, 45: 326-330.

43. Salonen, J.T. Non-insulin diabetes and ischaemic hearto disease. Br Med J 1989, 298: 1050-1051.

44. Pyorala, K., Laakson, M. \& Uusitupa, M. Diabetes and atherosclerosis: an epidemiologic view. Diabetes Metab Revg 1987, 3: 363-524.

45. Zimmet, P. \& Whitehouse, S. The effect of age on glucose tolerance: studies in a Micronesian population with a high음 prevalence of diabetes. Diabetes 1979, 28: 617-623.

46. Weintraub, B., Klein, L., Seelaus, P. et al. Importance of total life consumption of cigarettes as a risk factor for coronary heart disease. Am J Cardiol 1985, 55: 669-672.

47. Gordon, T., Kannel, W.B., McGee, D. \& Dawber, D.R. $\stackrel{\oplus}{\oplus}$ Death and coronary attacks in men who give up smokigg. $\overrightarrow{0}$ Lancet 1974, ii: $1345-1348$.

Kannel, W.B., Wolf, P.A., Castelli, W.P. \& D'Agostino, RA Fibrinogen and the risk of cardiovascular disease Framingham study. JAMA 1987, 258: 1183-1186.

49. Barrett-Connor, E.L. Obesity, atherosclerosis and coronary artery disease. Ann Intern Med 1985, 103: 1010-1019. 